\title{
REPRESENTACIONES SOCIALES DE LO POLÍTICO. CONVERGENCIAS Y DIVERGENCIAS DEL RELATO GENERACIONAL EN EL GRAN CONCEPCIÓN
}

\author{
PABLO SANTIBÁÑEZ RODRÍGUEZ* \\ RODRIGO GANTER SOLÍS ${ }^{* *}$
}

\begin{abstract}
RESUMEN
El presente artículo busca comprender y relacionar las representaciones sociales de lo político articuladas por distintas generaciones de secundarias y secundarios en el Gran Concepción, Chile. Se postula que las representaciones sociales de lo político construidas por jóvenes secundarios, se muestran contingentes al tiempo y espacio en que se produce. Esta contingencia a su vez posee su principal base en episodios de «reventones juveniles» que interpelan el devenir cotidiano de la política, re-articulando la forma en que se representa lo político. Es así como en la historia chilena post 1973 se plantea la existencia de tres relatos generacionales de lo político en secundarios, uno a partir de los 80, otro a partir del 2006 y un tercero originado en el 2011, que negocian lo político desde sus posiciones sociohistóricas.

\section{PALABRAS CLAVE: JUVENTUD (ES), RELATO GENERACIONAL, REPRESENTACIONES SOCIALES DE LO POLÍTICO}

* Magíster en Investigación Social y Desarrollo de la Universidad de Concepción, Chile. Licenciado en Educación de la Universidad de Concepción, Chile. Tesista Proyecto Anillo Juventudes SOC 1108.

E-Mail: pablosantibanezrodriguez@gmail.com.

** Doctor en Estudios Urbanos (PUC); sociólogo y docente del Departamento de Sociología de la Universidad de Concepción, investigador asociado Proyecto Anillo Juventudes SOC 1108.

E-Mail: rganter@udec.cl.

Este artículo se desarrolló en el contexto de la tesis de Magíster en Investigación Social y Desarrollo de la Universidad de Concepción titulada: «Juventud(es) y generaciones: representaciones sociales de lo político en el Gran Concepción», bajo la dirección del profesor Rodrigo Ganter Solís.
\end{abstract}




\title{
REPRESENTAÇÕES SOCIAIS DO POLÍTICO. CONVERGÊNCIAS E DIVERGÊNCIAS DO RELATO GERACIONAL NO GRANDE CONCEPCIÓN
}

\begin{abstract}
RESUMO
O presente artigo visa compreender e relacionar as representações sociais do político articuladas por distintas gerações de estudantes de ensino médio no Grande Concepción, Chile.

É exposto que as representações sociais do político construídas pelos jovens de ensino médio, mostram-se contingentes ao tempo e espaço em que são produzidas. Esta contingência por sua vez possui sua principal base nos episódios de «estouros juvenis» que interpelam o devir cotidiano da política, rearticulando a forma em que é representado o político. É assim como na História Chilena após 1973 é concebida a existência de três relatos geracionais do político nos estudantes de ensino médio, um a partir dos anos 80, outro a partir do ano 2006 e um terceiro no ano 2011, que negociam o político de suas posições sócio históricas.

PALAVRAS CHAVE: JUVENTUDE(S), RELATO GERACIONAL, REPRESENTAÇÕES SOCIAIS DO POLÍTICO

\section{SOCIAL REPRESENTATIONS OF THE REALM OF POLITICS: CONVERGENCES AND DIVERGENCES OF GENERATIONAL NARRATIVES IN GREATER CONCEPCIÓN}

\begin{abstract}
The present article seeks to understand and connect the social representations of politics from different generations of secondary school students in Greater Concepción, Chile. It is proposed that social representations of the realm of politics built by secondary students are contemporary to the period and space they are produced, and are, at the same time, mainly based on «youth explosion», questioning the day-to-day of politics and re-activating the way politics is represented. That is how Chilean post-1973 history states the existence of three generational political narratives in secondary students, portraying politics from their own socio-historical posture: the first from the 80 's, the second from 2006 and the final one from 2011.
\end{abstract}

KEY WORDS: YOUTH(S), GENERATIONAL NARRATIVE, SOCIAL REPRESENTATIONS OF POLITICS 


\section{INTRODUCCIÓN}

LA PRESENTE INVESTIGACIÓN SE propone estudiar las representaciones sociales sobre lo político configuradas por distintas juventudes en el Gran Concepción. Este relato busca poner especial énfasis el componente generacional capaz de dilucidar la habilidad para articular un relato sobre lo político por parte de secundarios y secundarias en distintos momentos históricos.

«Gran Concepción», nombre con el que se conoce a aquella área principalmente urbana que el Instituto Nacional de Estadísticas (INE) reconoce como una conurbación compuesta por nueve comunas: Concepción, Chiguayante, Hualpén, Penco, San Pedro, Talcahuano, Coronel, Lota y Tomé. La población reside principalmente en zonas urbanas $(97 \%)$, en donde destacan las ciudades de Concepción y Talcahuano. El inicio de su poblamiento obedece a tiempos prehispánicos, transformándose durante el periodo de la conquista española en la principal ciudad militar en la Capitanía General de Chile por su carácter de «frontera» con el pueblo mapuche. Escenario de batallas durante el inicio de la independencia en Chile y ofreciéndose como el principal contrapeso a la hegemonía de la capital Santiago durante el siglo XIX, esta zona se transforma en el siglo XX en un importante polo de desarrollo industrial al aplicarse el Modelo Sustitutivo de Importaciones siendo sacrificada por el modelo neoliberal aplicado desde la década de los ochenta. Durante el periodo de estudio principalmente desde espacios educacionales se levantan movimientos que ponen en cuestionamiento ciertos paradigmas de la política que se buscaba plantear, durante los años ochenta principalmente desde la Universidad del Biobío y Concepción, y durante el 2006 desde establecimientos educacionales como el célebre «Liceo Acuático» de Lota.

El golpe de estado del 11 de Septiembre de 1973 desestructura el fantasma populista caudillesco que articulaba un estado amable para la ciudadanía (Salazar, 2012). Posterior a esto, principalmente entre los años 1983 y 1987, surgen movilizaciones estudiantiles/populares que estructuran la lucha contra el gobierno autocrático de Augusto Pinochet. La lectura del tiempo histórico que viven les obliga a poner en práctica herramientas sedimentadas en la memoria de la juventud (Salazar \& Pinto, 2010). No es extraño que sea principalmente en esta década donde surjan los primeros estudios sobre juventud (Aguilera, 2009). La dictadura en Chile comienza a despedirse a partir del plebiscito de 1988, cuando la opción del «No» vence con un 55\% de la 
votación y expresa su decisión de volver a organizarse como país en torno a una democracia, durante 1989 se logra un acuerdo entre la oposición y el gobierno para eliminar los elementos más autoritarios de la constitución que es aprobado también por un consenso, generan en conjunto un complejo marco de reglas que dirigirán el juego político futuro (Munck, 1994).

La estabilidad política lograda en Chile durante estos años es lograda a expensas de la participación y una genuina construcción de sociedad democrática. Las elecciones desarrolladas durante la década de los noventa no son capaces de disminuir el poder de las instituciones no democráticas, situación que termina siendo zanjada por grupos altamente tecnocráticos (Drake, 2000). Es así como se va precisando el diagnóstico de crisis en la democracia participativa demostrada por los bajos índices de inscripción presentados durante la actual década sobre todo en la juventud ${ }^{1}$ y una desconfianza de estos en las instituciones públicas y en los políticos que en ellas participan (CEJU, 2010). Una de las principales hipótesis es la de la «desafección política», materializada en una falta de interés en participar en tales espacios (Candía, 2004). Las movilizaciones registradas por parte de secundarios y universitarios durante la segunda mitad de la primera década del presente siglo e inicios de la segunda demostrarían la inexistencia de esta apatía (Zarzuri, 2006). Se constituye así un espacio en el cual los jóvenes se comienzan articular en espacios alejados de lo «tradicional» (Reguillo Cruz, 2012), constituyendo distintos espacios de participación en grupos juveniles, deportivos, sociales y culturales que llevan lo político a una práctica cotidiana (Salazar y Pinto, 2010).

El año 2006, miles de estudiantes secundarios se mantuvieron movilizados durante más de dos meses. Los estudiantes de enseñanza media desarrollan prácticas que incluyen interpelaciones directas a autoridades y tomas de establecimientos educacionales, en lo que se denominó la «Revolución de los pingüinos» (Bellei y Cabalin, 2013). El movimiento articula como principal demanda la gratuidad del transporte y de la Prueba de Selección Universitaria (PSU); no contento con esto, los secundarios son capaces de estructurar demandas que van en contra de bases legales que definían la educación hasta el mo-

1 Posible de observar en la V Encuesta Nacional de Juventud (2007) que indica que solo el 30,7\% de los jóvenes se encuentran inscritos en los registros electorales. 
mento (como la LOCE) ${ }^{2}$ y que ponen en el centro la herencia dictatorial de la democracia chilena. Este movimiento sentará las bases de un movimiento estudiantil masivo y significativo, el del 2011, estructurando prácticas que permitirán la lucha en el ámbito educacional (Bellei y Cabalin, 2013).

A partir de lo anterior es que el 2011, parte de estos secundarios del 2006 que ahora pertenecían a la educación terciaria del país articulan un nuevo movimiento, denominado el «invierno chileno» (Barrionuevo, 2011) en alusión a la «Primavera Árabe» existente en esos momentos. A un mes de la primera movilización registrada durante el año 2011 ( 8 de Abril) el movimiento es capaz de duplicar la convocatoria llegando a casi 20.000 personas. Lo anterior sería el inicio de un movimiento que solo en Santiago sería capaz de convocar a más de doscientas mil personas durante las siguientes treinta y seis semanas de protesta (Bellei y Cabalin, 2013). Es así como se desarrollan intervenciones de espacios públicos, en donde con bailes y disfraces simbolizan la muerte de la educación pública (Huffington Post, 2011); o se dedican a trotar durante 1.800 horas alrededor de la moneda, buscando incluso alcanzar otros lugares del país (La Nación, 2011). A lo anterior se suma el repertorio establecido en momentos anteriores como el «mochilazo del 2001» o el «pinguinazo del 2006», como lo son las tomas, marchas masivas, huelgas de hambre y cacerolazo (Segovia y Gamboa, 2012).Las redes sociales alcanzan un nuevo estatus gracias a su capacidad para establecerse como plataforma capaz de articular y organizar el movimiento social. Aparece Twitter y el Trending Topic «\#Nosvemosenlascalles» y por otro lado la convocatoria mediante Facebook a marchas y acciones como las descritas en el párrafo anterior (Cardenas, 2014).

La construcción socio histórica de la participación descrita anteriormente, enfatiza la relevancia de la juventud como actor capaz de articular un relato sobre la forma en que nuestra sociedad se organiza. Este texto se encuentra organizado en cuatro momentos centrales.

\section{CONSIDERACIONES TEÓRICO-METODOLÓGICAS}

Las líneas que guían el trabajo investigativo se pueden ver sintetizadas en el esquema presentado a continuación. Este punto se encargará

2 Ley Orgánica Constitucional de Enseñanza promulgada por Augusto Pinochet el día antes de salir de la Moneda (10 de marzo de 1990). 
principalmente de detallar las bases teóricas y metodológicas que permitan interpretar los hallazgos realizados.

Uno de los temas fundamentales que deben ser trabajados para delimitar nuestro trabajo es el de «representaciones sociales» y su aplicación en la política; este concepto lo entenderemos como aquella forma del conocer que es producida y compartida al interior de una agrupación participe de prácticas sociales comunes y que están ubicadas e insertas en un determinado espacio de la estructura social (Jodelet, 1985; Moscovici, 1984). Tal constructo conformado por estos grupos sociales sería capaz de constituir una forma de accionar de los miembros del grupo permitiendo la estructuración de ciertos comportamientos, significando y estableciendo la posibilidad de constituir adhesiones a ciertos elementos de la realidad social (Jodelet, 1985), su capacidad es en convertir lo extraño en algo familiar y lo invisible en algo capaz de ser percibido (Farr, 1983). A partir de la propuesta desarrollada por Moscovici derivan una serie de líneas de estudio e investigaciones asentadas en su propuesta inicial dinamizando y profundizando aún más su construcción teórica y metodológica; una de las más importantes es la teoría del núcleo central (Kornblit, 2004). La hipótesis central de esta teoría sostiene que existe una jerarquía y tras de ella una estructura que ordena estos componentes de naturaleza disímil, unos serán parte del núcleo central, y otros de elementos periféricos (Abric, 1993; 2001).

Dentro de los diferentes grupos productores de representaciones sociales encontraremos el «juvenil», conceptualización construida a partir de un contexto histórico y espacial determinado (Bourdieu, 1990). Pese a lo anterior, no podemos negar su presencia como actor y productor de representaciones (Chung y Probert, 2011); la entenderemos como un constructo sociocultural dinámico alejándose de aquella posición en donde estos son reducidos a una categoría de edad; retomando una suerte de reivindicación epistemológica frente a una perspectiva histórico-social primordialmente adulto céntrica (Salazar y Pinto, 2010). La propuesta es construir un conocimiento desde un enfoque interpretativo (Reguillo, 2012) entendiendo que los imaginarios juveniles no se constituirán completamente autónomos frente a las instituciones, pero que al mismo tiempo estos no serán simples reproductores de las retóricas y discursos de aquellas.

A partir de lo anterior surge la necesidad de caracterizar el concepto de «generación» permitiéndonos superar la idea «juventud» por la de «juventudes» ya que agrega al ejercicio la variable temporal; y es que al hablar de generación, hablamos de una representación social 
específica, de un relato y un discurso de pertenencia, de lejanía y al mismo tiempo de herencia de otras generaciones (Muñoz Tamayo, 2011) una misma «conexión generacional»; a partir de distintos grupos con sus propias subjetividades identitarias. Salazar y Pinto (2010) producen una forma de acercarse al objeto de estudio principalmente vinculada a generaciones políticas con orientación transformadora, articulando en el devenir de la historia de nuestro país las trayectorias de juventudes que justamente adquiere este carácter dialéctico con su pasado explicitado por Mannheim (1993). A lo anterior se sumará el libro Generaciones. Juventud universitaria e izquierdas politicas en Chile y México (Universidad de Chile-UNAM 1984-2006) (Muñoz, 2011) que propondrá con mayor sistematicidad una propuesta de análisis sobre lo generacional. ${ }^{3}$

Luego del desarrollo de los primeros momentos de la investigación, como investigadores somos capaces de dilucidar que existen ciertas propuestas desde la filosofía política que permiten acercarnos a la forma de producción del relato generacional, principalmente de las juventudes del siglo XXI. En la actualidad podemos encontrar el contraste entre dos corrientes: el «agonismo» y la «deliberativa».

La corriente de los «agonistas» tienden a poseer sus puntos de centrales en dos temáticas: i) su vínculo inicial con las propuestas de Althusser y ii) su crítica a la posibilidad de consenso en los valores que plasman la «política».

Para Mouffe (1999), al plantearse el ideal de acabar con los antagonismos mediante el uso del consenso se otorga un vehículo para limitar la aparición del pluralismo. Para Rancière, en una democracia no se logra la situación de interlocución ideal planteada por Habermas, por lo que el alcance de cierta racionalidad universal se vuelve imposible, la democracia no tiene la capacidad para acabar con los

3 Articulándola bajo los siguientes puntos. - Crítica a la idea del ritmo histórico en el asunto generacional. • Generación uno de los elementos para comprender el trazado sociohistórico, no el único. Generación asociada a sociedades dinámicas, principalmente modernas. Generación como construcción de las juventud(es). • Juventud como eje de lo generacional. - Articulación relacional, identitaria y diferenciadora de la generación. • La generación de enlace como nexo entre las viejas generaciones y las generaciones nuevas. - Generación como abordaje a la construcción ideológica y discursiva de la juventud. • Generación como fruto de análisis comprensivo del científico social. Generación y su diferencia radical a lo etario. 
conflictos y las divisiones (Rancière, 1996:125), lo que queda es asumirlos.

Su propuesta incluirá dos espacios. Aquel espacio de lo público caracterizado por la organización y administración de la comunidad y su consentimiento que descansa en la jerarquización de lugares y funciones, que se le llamará «policía». Esta lógica «disciplinará» los cuerpos, se les asignará roles y objetivos. Será capaz de establecer lo visible y al mismo tiempo lo enunciable (Rancière, 2010:102). En oposición a «la policía», para la verdadera articulación de un sistema democrático, se articulará la «política». Este proceso tendrá como principio guía el de la igualdad y su distribución en las partes que componen la comunidad (Rancière, 1996). Este proceso tiene que ser desarrollado a partir de una capacidad de agencia de la colectividad integrante del «demos». La construcción de una democracia distinta a la del consenso, es la de la «democracia radical», la propuesta de Mouffe (1999) buscará proponer como elemento central de cohesión frente al carácter polémico de la política, la idea de los «derechos democráticos». Caracterizarlos de tal forma permite alterar el hilo hegemónico de su representación, dando luz a una mayor cantidad de luchas democráticas. Lo anterior exigirá una equivalencia estructural en la posición de las luchas, en donde pese a su diferencia ocupen una posición común, la de la lucha por los «derechos democráticos» (Mouffe, 1999:40).

Al definir que la política será un espacio de los sujetos y la acción, Rancière nos indicará que estará específicamente relacionada con la subjetivación, ya que las identidades de los sujetos protagonistas no estará dada sino que se estará dando en el momento en donde se corre «por fuera» de la lógica policial (Rancière, 1996:59). Así, el concepto de ciudadano queda a lo menos en tensión debido su carácter «dado» en base a derechos y responsabilidades clásicamente definido por el liberalismo. (Mouffe, 1999:60), lo que implicará una relectura. Esta persistencia del concepto de ciudadano en el caso de nuestro país será reconocida por Gabriel Salazar en Movimientos sociales en Chile al identificar su aparición en lo público como «Movimiento ciudadano», sobrepasando el movimiento de masas. Siendo reconocido incluso como el momento culmine de una construcción y germinación «por abajo» y que ve en el «pingüinazo» su primer asomo.

Para dar respuesta a los objetivos planteados por la investigación, el enfoque metodológico es mixto subsidiario (Cual $\rightarrow$ Cuan) en dos etapas (Creswell, 2008). Para tal trabajo se decidieron desarrollar gru- 
pos focales, permitiéndonos comprender de una manera más detallada las representaciones sociales privilegiando una profundización del fenómeno por sobre una generalización (Ruiz, 2012). Las herramientas seleccionadas se orientaron a reconocer lo complejo de la realidad social promoviendo la interacción de lo cualitativo y cuantitativo para dar respuesta a las problemáticas que buscamos investigar. La escuela principalmente francesa durante los años 50 y 60 en su carácter semiológico - representada en un inicio por Barthes (1977) y posteriormente por Algirdas Greimas (1987) — destacan el análisis sincrónico del lenguaje además de optar por generalizarla ideología como presente en todo discurso (Larraín, 2010). Por lo anterior parte de un análisis eminentemente cualitativo como lo es el Análisis Estructural del Relato (Bartes,1977; Greimas,1987) para posteriormente ser apropiado por estrategias de análisis cuantitativas (Análisis de redes y análisis de conglomerados) y finalmente proponer modelos de acción simbólico, de carácter cualitativo (Remy,1996; Martinic,1992).

Durante la fase de campo de la investigación (septiembre del 2014 y enero 2015) se realizaron seis grupos focales donde se convocó a jóvenes que fueron estudiantes secundarios: a) durante los años 80, particularmente los asociados con la coyuntura del plebiscito del 88 ; b) durante el inicio del siglo XXI, particularmente los asociados con la coyuntura del año 2006 y los llamados «pingüinos»; c) durante la coyuntura abierta por el movimiento estudiantil el año 2011. Cada una de estas convocatorias incluyo por separado el componente de género para explorar las posibles continuidades, particularidades y tensiones más concretas.

\section{REPRESENTACIONES SOCIALES DE LO POLÍTICO EN DISTINTOS RELATOS GENERACIONALES DEL GRAN CONCEPCIÓN}

El producto del análisis estructural del relato, la articulación de redes reticulares del relato y su posterior análisis por conglomerado, nos muestra como hallazgos centrales a nivel estructural y contextual los siguientes elementos.

\section{CONVERGENCIAS DEL RELATO GENERACIONAL EN TORNO AL BIO BÍO}

En un primer momento se hace necesario establecer aquellas partes del relato generacional, o aquellas representaciones sociales de lo 
político, que son capaces de mostrar un actuar similar en cada uno de las generaciones secundarias estudiadas.

a) La militancia en tensión:

críticas en torno a la política tradicional de izquierdas.

Los hallazgos nos permiten evidenciar la crisis de la militancia política, este relato pese a presentar ciertas especificidades dependiendo de la generación estudiada, se muestra constante en el tiempo. El ícono de esta crisis es el Partido Comunista el cual se observa cuestionado en cada uno de los grupos.

En el caso del relato generacional secundario de los ochenta podemos interpretar este movimiento como herencia de la capacidad dictatorial para vaciar de sentido ciertos conceptos, y es que «La organización social crea momentos... buscando el medio ambiente para crear una unidad de sentido entre el yo y los demás. Pero son los acontecimientos históricos que parecen ofrecer las oportunidades cruciales para la construcción de las nuevas versiones de estos significados» ${ }^{4}$ (Abrams, 1982:256). La búsqueda por parte de la dictadura de adueñarse del discurso sobre el Partido Comunista en específico (y de los partidos de oposición en general) y vaciarlo de significados anteriores radica en la necesidad de apropiarse de una parte del relato sobre los partidos otorgando poder sobre las representaciones de lo político y por consiguiente sobre la sociedad, ya que debemos reconocer que «la producción del discurso está a la vez controlada, seleccionada y redistribuida por un cierto número de procedimientos que tienen por función conjurar los poderes y peligros, dominar el acontecimiento aleatorio y esquivar su pesada y temible materialidad» (Foucault, 2002:5). Lo anterior surge fundamentalmente a partir del miedo lo que podríamos definir como etapa terrorista, esto «como fase de una dictadura revolucionaria en el que el derecho, que define lo prohibido y lo permitido, y el saber que define el proyecto se imponen privilegiando los castigos. El orden se afirma sobre el terror» (Moulian, 1997:171).

4 «The social organization of the life cycle creates moments of more or less acute exploration-searching the environment to create a unity of meaning between the self and others. But it is historical events that seem to provide the crucial opportunities for constructing new versions of such meanings» Abrams, P. 1982. Historical Sociology. Ithaca, New York: Cornell University Press. 
No, yo recuerdo que pregunté qué es JJ.CC., y me dijeron cállate, no se puede nombrar, y decía uy qué terrible, que significará, y debe ser algo terrible..., si tú la decías te iban a llevar preso (G1, Myriam).

La palabra Comunismo pasa a ser algo «que no debe ser dicho», esta sedimentación en el relato se muestra inalterable pese a la acción del plebiscito. En palabras de Mayol «La ecuación fundamental de los años ochenta, caracterizados por la represión, el toque de queda y la elaboración de un proyecto de transición política... a partir de la amenaza constante el retorno de la violencia» (Mayol, 2012:242).

Cuando se hablaba de los comunistas... los hacían parecer como un movimiento terrorista, no como partido político (G2, Roberto).

Esta persistencia en el relato sobre el Partido Comunista podría ser interpretada a partir de la tardía acción de aislar aquellos argumentos «radicales» que lo ponían en la extrema izquierda del país, principalmente vinculados con la idea de la Rebelión Popular de Masas; la cual no coincidía con los tiempos de «moderación» que la nueva transición requería (Venegas, 2009), y es que durante este proceso «vastos sectores de la clase media retrocedieron, temerosos de las formas más radicales de la movilización. Esto condujo al aislamiento de los grupos más militantes y los más inclinados a la línea dura, con métodos que podían causar disturbios y allanar el camino para un colapso del régimen» ${ }^{5}$ (Garretón, 2003:128). Por otro lado, podríamos comprenderlo como cierto «sistema de disposiciones duraderas y transponibles, estructuras estructuradas predispuestas a funcionar como estructuras estructurantes» (Bourdieu,1992:88) capaz de mantener una representación sobre el Partido Comunista coincidente con lo plasmado en dictadura.

Ya desde una vertiente más crítica y directa, el relato generacional de los secundarios del 2006 cuestiona las distintas estrategias y prácticas políticas que desarrolla el Partido Comunista para el logro de sus objetivos. Surge la idea de que esta forma de actuar política atro-

5 «Thus vast middle-class sectors retreated, fearful of the more radical forms of mobilization. This led to the isolation of the most militant groups and those most inclined to more hard-line methods that would cause unrest and pave the way for a regime collapse» (Garretón, 2003). Incomplete democracy: Political democratization in Chile and Latin America. UNC Press Books. 
pella la diversidad y heterogeneidad en las posiciones frente a los objetivos que una organización se plantea.

Yo creo que la única vez que se me pasó por la cabeza (ser comunista) así por mona me imagine a mí misma convertido en mi mamá, mi papá o mi abuela, y dije no esto no es para mí, para terminar haciéndole el caso a otro (G3, Daniela).

Bajo esta lógica podríamos hablar de una capacidad policiaca del Partido Comunista en su comportamiento dentro de la movilización principalmente articulada en base a la búsqueda de la homogeneidad y su práctica de «cuadro». Lo anterior rompe con el actuar secundario del 2006 que buscaba en la asamblea un espacio de reconocimiento de una práctica conjunta pero heterogénea, que en palabras de Rancière permitiría la «presencia de dos mundos» (Rancière, 1996:42), la presencia de la política.

Partieron a la CUT y fueron a pedirle al dirigente de la CUT a que llamara una huelga general y ahí a la CUT se le hizo, los locos dijeron no... ahí cachamos que el Partido Comunista estaba vendiéndonos..., la concertación se había comprado al partido comunista (G4, Mauricio).

El relato generacional de secundarios del «invierno chileno» mantiene el cuestionamiento a ciertos elementos anteriores, y agregan unos nuevos. La crítica a esta búsqueda policiaca de articular la práctica política, incluso se hace práctica en las movilizaciones. ${ }^{6}$ La mantención del ideario de la heterogeneidad planteado por los secundarios pone en tensión estas prácticas con planteamientos que buscan «que reconozcamos la diferencia, lo particular, lo múltiple, lo heterogéneo, o sea todo aquello que el concepto abstracto de hombre excluía» (Mouffe, 1999:33) en base a una democracia radical; y es que los jóvenes de inicio del siglo XX, plantean un respeto «casi religioso» por el individuo (Reguillo, 2012).

Lamentablemente se ha ensuciado tanto con el partidismo actual, porque ya no es como una democracia... yo siento que en Chile la democracia se ha oxidado tanto que ya es como una aristocracia pero partidista... con las alianzas estúpidas que hacen ahora entre partidos que no tienen nada en común (G6, Derek).

6 En donde desde distintos grupos principalmente ubicados «más a la izquierda» se grita la consigna «Los pacos de rojo son los peligrosos». 
La capacidad de negociación que tiene el Partido Comunista, y la forma en que hace uso de sus figuras públicas se ponen en el centro de la discusión. Por un lado, la capacidad de articular alianzas y consensos con partidos que durante años no se muestran atentos a las demandas del movimiento social y por otro lado, las acciones que llevan a «regalar» figuras que construyen su capital político gracias a este movimiento, ponen en discusión la «lealtad» del Partido Comunista con las movilizaciones, lo que profundiza una progresiva difuminación entre las nociones de lo político desde la derecha a la izquierda; debilitando la idea del enfrentamiento de proyectos políticos entre «antagonistas» para dar paso a una de «competidores» (Mouffe, 1999).

Los cambios no estaban con los partidos políticos y no entendía porque ellos tenían que tomar las decisiones... le compré a la Vallejos en mucho tiempo y que la loca este allá arriba ahora (G5, Francisca).

Yo le creí a la Vallejos... y salía y decía si la Camila Vallejos la cuestión y fue como... mi orgullo... me decepciona aún los partidos políticos, porque al final lo que uno piensa es que está maquinada por su partido político... nunca me ha interesado y no creo que me interese a futuro (G5, Fabiola).

Así se configura un escenario que se muestra hostil a aquellos partidos capaces de reducir la heterogeneidad y limitar el proyecto biográfico individual de sus integrantes. Esta forma de representar la podríamos entender desde la perduración de un habitus capaz de estructurar experiencias pasadas y funcionar como matriz estructurante sobre los partidos tradicionales de izquierda (Bourdieu, 2012) capaz de reproducirse a partir de la historia (Bourdieu, 2011) configurada en este caso, por la dictadura. Por otro lado, podríamos hacernos cargo del proceso de carácter global que muestra una pérdida de confianza en las alternativas institucionales de la democracia tradicional (Sandoval, 2003) e identificar la irrupción de un modelo democrático «radical» (Mouffe, 1999) desde los jóvenes, promoviendo una nueva forma de asociatividad y organización que mediante prácticas no convencionales constituyen formas de entender la política (Funes, 2003) y que en el caso de la izquierda tradicional, se vería aún más tensionado por la crisis de las agrupaciones de «vanguardia».

Me acuerdo ese año igual, marchamos con los del hospital... con los trabajadores... salió lo de Aysén, entonces era como gente que, que em- 
pezaba a tomar, como se dice, el toro por las astas y decir que no que no estaban de acuerdo con lo que el gobierno les decía (G5, Francisca).

b) Justicia como principio articulador de lo político. Transformaciones sobre el Estado

Tal vez este elemento sea uno de los centrales de la presente investigación. Al realizar los modelos simbólicos se hace constante la idea de la justicia como principal objeto del relato de los grupos generacionales; por lo tanto, núcleo simbólico de la práctica política. Para Aristóteles, a los seres humanos se nos entrega la capacidad única de la palabra, capaz de manifestar desde sus comienzos la dicotomía entre lo útil y lo nocivo, lo justo y lo injusto (Aristóteles, 2006). Desde este momento en adelante, este concepto será central para la discusión sobre lo político: «La política comienza precisamente allí donde dejan de equilibrarse pérdidas y ganancias, donde la tarea consiste en repartir las partes de lo común» (Rancière, 1996:8).

Podríamos entrar en la discusión de que los 80 plantean en sí la democracia como objeto, ¿pero no es acaso la expresión práctica de una necesaria justicia castrada por el terrorismo de estado liderado por Augusto Pinochet? ¿No es acaso la expresión práctica de una necesaria distribución del poder y los derechos políticos?

Claro, acá lo veía como por el lado de los derechos de las personas que no fueran transgredidos y pasar a llevados y juntamente con eso también la responsabilidad de las personas frente a un montón de reglas, o leyes que a lo mejor eran injustas, en ese tiempo, y que había que hacer cambios, había que hacer cosas pero se escuchaba, pero no se lograban los objetivos (G2, Guillermo).

El «pingüinazo» y el «invierno chileno» se muestran aún más explícitos al buscar tensionar aquella estructura educacional que constantemente burlaba la idea de la justicia. Utilizando el sistema educativo como institución reproductora del poder económico, social, político y cultural de pequeños grupos.

Un profesor, estaba el vidrio quebrado en la ventana y nos dice miren pal frente ahí están sus jefes... ahí están los que ustedes le van a tener que agachar la cabeza (Del Charles de Gaulle), estaban saliendo de clases parece, entonces como que miraba y existía ese comentario... Entonces, ese tema como el movimiento social a quien le pertenecía... Me 
acuerdo que el día que fueron a dar la charla (PDI), los tipos dicen ya los que son de Tucapel Bajo, de la John Kennedy y Boca Sur, no pueden postular (G4, Esteban).

Como se dijo anteriormente, la discusión en torno a la forma en que se equilibran las pérdidas y ganancias dentro de una comunidad al repartir aquellas cosas que se comparten -es decir el patrimonio colectivo de la sociedad - marca el inicio de la política (Rancière, 2006). Frente a esto no nos debería extrañar que el ideal de la justicia articulara el relato de lo político en cada una de las generaciones. El ascenso de la participación política en nuestro país a partir de estos reventones juveniles vendría a ser justamente la consecuencia de la discusión sobre «lo justo» y la forma en que el estado postdictadura estaba funcionando a partir de una lógica desigual, evidenciada sobre todo en su sistema educativo, en «Chile se ha obsesionado con la sala de clases y... Pero es uno de los países donde menos influye la escuela» (Mayol, 2012:200).

Un buen ciudadano... trataba de algún medio, con comprometerse con la lucha por la igualdad... tiene que ver con eso, que todos podamos acceder a los beneficios de la riqueza que tenía como nuestro país, eso era como ser un buen ciudadano (G3, Gabriela).

c) Reventones juveniles y crisis de la estructura representacional de lo político (subjetivación): hitos como ruptura de los modelos hegemónicos de lo político

Un elemento de convergencia entre los distintos grupos de secundarios participes de esta investigación, es la relevancia de lo vivido para la forma en que representaron la política. Se hace evidente su presencia en el núcleo de las representaciones sociales, por otro lado aparecen en cada uno de los modelos simbólicos como «ayudantes» del logro del objeto.

Para mí, yo tengo como un antes y un después en el concepto de estado durante el $2011 \ldots$ antes era el estado que te daba el libro de historia, esto de los tres poderes del estado legislativo, ejecutivo y judicial, y era la autoridad, el poder, el jefe (G5, Javiera).

Esta manifestación del disenso como presencia de dos mundos muestra la capacidad para configurar un espacio de retorno de lo político. 
No pero claro, el concepto de movimiento social, previo y post 2011 o la marcha de los pingüinos, nooo, se nos abrieron los ojos increíblemente (G6, Jonatán).

Los espacios que buscan ser mostrados asépticos por los detentores del poder (que desarrollan dispositivos justamente para dispersar el disenso, dispersar lo político) se constituyen justamente como aquellos escenarios de la manifestación del sujeto.

Ese como cambio de espacios porque como la efervescencia del movimiento social... ha sido la tónica del dos mil seis para delante de ejercer digamos y dignificar la apropiación mediante la protesta social po, y mediante la expresión social en la calle (G3, Camila).

Los análisis muestran la capacidad que adquieren los actores en estos espacios para representar lo político de formas distintas a las existentes antes de su participación en ello.

Como decía la Javiera que era una exhibición pública, esto como de expresar el poder callejero... siento que en el $2011 \ldots$ el empoderamiento de la sociedad y de todas estas manifestaciones... generó un cambio como decía la Panchi, un antes y un después (G5, Camila).

Esto surge dada la posibilidad de nutrir desde lo cotidiano y local lo político articulando elementos que mediante la tradición no se habían establecido. Es así como estos reventones juveniles se transforman en espacios fértiles para la subjetivación, reconfigurando el campo de experiencia del sujeto juvenil.

Después, en el 84-85 ehh, cuando ya comienzan estos, estas, protestas constantes, yo ya iba en el Liceo y tenía que viajar y para mí era una molestia que se tomaran las micros y no pudiera ir a clases, y para mí no ir a clases era horrible. Como los terroristas podían hacer eso. Entonces cuando comencé a abrir mis horizontes, 84 y 85 , que hizo clic con la muerte de esos tres profesores, entonces yo ahí, cambie en realidad mi estructura mental... fue como madurar y tener un pensamiento propio (G1, Rosalía). 


\section{DIVERGENCIAS DEL RELATO GENERACIONAL EN TORNO AL BIOBÍO}

Luego de caracterizar aquellas posiciones que muestran comportamientos convergentes se hace necesario estudiar aquellos momentos de «ruptura». Estas líneas de fractura en la representación social de lo político son expresadas a partir de la elaboración de un relato generacional.

\section{a) El resurgir del ciudadano}

Debemos partir diciendo que el concepto de ciudadano se muestra constantemente representado en el relato de los distintos grupos estudiados. La diferencia recae en la forma en que este concepto se muestra articulado. El ciudadano del relato generacional pingüino del 2006 podría ser tachado de «terrorista» por el relato generacional «policiaco» de los 80. El que participa de los «asuntos de la polis» adquiere motes distintos dependiendo del relato generacional por el cual es producido, de «poblador/terrorista» a «opositor», para luego entrar en el siglo XXI con un concepto «recargado», el secundario del 2006 y del 2011 pese a no votar, se constituye como ciudadano.

Lo observado de la presente investigación nos muestra la capacidad que tiene la dictadura para «formalizar» el concepto.

Yo me imaginé inmediatamente a mis vecinos igual, que eran hombres de familia, con sus hijos, casi Opus Dei, iban todos a misa, todos correctos, como aquel que sigue las reglas, que era lo que uno veía. Ahora que hacían no sé, pero lo que uno veía, los que seguían las reglas. Ese es para mí el buen ciudadano (G1, Rosalía).

Este relato aséptico de ciudadanía, se encarga de alejar el concepto de cualquier forma de participación y protesta en contra de la dictadura, homologándolo a un «buen vecino» o «buen cristiano» por sobre un actor político que busque poner en práctica ciertas acciones que vayan en contra de la dictadura. Es así como se muestra como un concepto ajeno vinculado a un escaso número de personas de nuestro país. Y es que, del aprendizaje desarrollado por los defensores de la «unidad nacional» surge la amenaza de los reventones juveniles, que en los 60 promovían discursos renovadores y reformistas; por lo que se encargan de proyectar una imagen de sociedad civil que debía rechazar la 
politización en defensa del proyecto de reconstrucción nacional (Muñoz, 2004).

No cuestiona nada, porque mi papá no opinaba, mi papá no decía ni sí ni no. Entonces eso, eso, esa es la imagen de un buen ciudadano (G1, Carmen).

Desde el 2006, surge un proceso de reagrupación del relato en torno a la ciudadanía. Es así como el concepto claramente delimitado por distintas instituciones encargadas de formar en base a «lo legal» tiene un desplazamiento hacia uno articulado «desde la calle».

A muchos nos pasó ese año, de que a los viejos les sorprendía que no teníamos miedo a salir a la calle, para nosotros era casi un juego así, o a Juanito lo agarraron los pacos, y ahí, había que ir a esperar a la comisaría, y era como que chuta y a muchos le quedaba en la retina eso de que era súper brígido ( $\mathrm{G} 4$, Mauricio).

Las prácticas que desarrollan los secundarios también permiten su enriquecimiento desde lo local. La sedimentación experiencial desde lo cotidiano, permite re significar ciertos elementos importantes de la ciudadanía, como lo son los valóricos. Así se hace necesaria una práctica no solo política, sino también comunitaria preocupada del resto de los vecinos, articulada en el barrio (Reguillo, 2012).

Bueno, para mí era primero que todo comprometido, que hiciera algo por cambiar lo malo que ocurría en el favor de la sociedad de ese tiempo, enérgico, y que tratara con actos mínimos mejorarlo. Qué sé yo, juntas de vecinos, ya, tratar de mejorarlo al nivel población que eso es ayudar en algo a mejorar la sociedad de a poco..., no necesariamente si es conveniente para él (G4, Richard).

Así se constituye como el sujeto que tiene como principal objetivo buscar la justicia en los relatos posteriores al fin de milenio (en un espacio local, y también en uno nacional). Esto implica una lectura ya a alejada de mecanismos políticos tradicionales y más vinculada con los movimientos sociales que se desarrollan. La participación del ciudadano se dará mediante la acción, no mediante la representación.

Primero, si mantenía el tema de respetar la ley dentro de lo que fuera necesario, o sea, si no te dan permiso para salir a la calle, y era necesario, tenía que hacerlo... participaba de su organización y no tenía mie- 
do..., pateaba la mesa cuando era necesario y participaba de su organización local (G3, Paula).

La ciudadanía del inicio de siglo, descubre la conceptualización insuficiente y limitada de los relatos del siglo XX, que articula la idea en base a una concesión en contraste con la de una mediación entre a heterogeneidad reconocida por los nuevos movimientos sociales (Reguillo, 2012). La ciudadanía deja de ser un estatus legal y pasa a ser una forma de identificación con el tejido político nacional y global (Mouffe, 1999).

\section{b) De parroquias, profesores, compañeros y redes sociales: espacios de articulación del aprendizaje político.}

Como se indicó anteriormente, la información posee un grado de centralidad importante en cada uno de los relatos articulados por secundarios durante el transcurso del estudio. Junto con lo anterior debemos identificar aquellos elementos que funcionan como fuentes de aprendizaje político. Es así como identificamos una trayectoria que diferencia a las generaciones a partir de las fuentes de cognición política que eligen como válidas.

Yo me acuerdo en la parroquia de repente se corría la voz de que iban a dar la batalla de chile en VHS en una pieza chica, y hedionda y todos fumando y calladitos porque eso era prohibido (G1, Jessica).

El carácter mediado de la cognición política (Lau y Sears, 1986) exige el filtro constante de sus fuentes. Su carácter modelado por dispositivos hegemónicos y posteriormente por los ciudadanos, exige una constante actualización de las representaciones sociales sobre las fuentes legítimas de cognición política.

En ese tiempo para mi eran los panfletos que uno veía, o ya el rallado en la muralla ahí te ibas dando cuenta, no se pa, paro de este 14 y 15 por muerte no sé qué compañero y yo comenzaba... nos encerraban en la UBB los pacos nos esperaban afuera, y yo iba con los (panfletos) y hacía análisis... (G2. Jaime).

Los secundarios de los años ochenta participes de esta investigación identifican dos fuentes fundamentales del aprendizaje político. En un primer momento encontramos a la iglesia, que otorga espacios en el 
cual distintas formas de entender lo político se sitúan para su apropiación, difusión y discusión.

Que era como lo que se escuchaba en ese momento, por lo que mí, cuando la democracia cuando la escuche fue en unos sketches cuando en la iglesia estábamos todos ahí, e íbamos a escuchar esas canciones de protesta, no sé a Justiniano como en cuatro paredes y hacían un sketch de «Democracia, Democracia» y venían los pacos, y después. Pero era verdad, eran como unos sketches en esa época (G1, Rosalía).

Por otro lado, surgen los profesores, que en momentos donde podían alejarse de la propuesta formal de significados sobre lo político, entregaban espacio, experiencia e información que permitía conocer mejor la política de la época.

Y yo ya había estado en el liceo este profesor que rompió como los esquemas de a clase correctita y nos empezó a hablar sobre lo terrible que había sido el asesinato de los profesores que yo hasta ahí no había entendido nada (G1, Rosalía).

El cambio en las fuentes de información a partir del «pingüinazo», surgen de una crítica evidenciada por distintos teóricos de la educación (Althusser, 1988) (Bernstein, 1993) (Bourdieu et al., 2003) (Willis, 1988) al carácter reproductivo de los sistemas educativos, diagnóstico que se sintetiza en la frase «Todo sistema de educación es una forma política de mantener o de modificar la adecuación de los discursos, con los saberes y los poderes que implican» (Foucault, 2002:48). Las nuevas fuentes protagonistas del aprendizaje político se constituyen en un espacio «la toma» y con un actor fundamental «los compañeros».

Yo creo que hubo un encaje ahí perfecto con respecto a esos temas, yo creo que por lo menos la gente con la que yo compartí en la toma del liceo de niños y de los otros liceos, del Enrique Molina, digamos que era gente con la que nos juntábamos y que íbamos a las marchas y que marchábamos por las calles y no por la vereda (G3, Gabriela).

Una de las acciones políticas que constituyen parte importante de los métodos de presión de este movimiento, comienza a desarrollarse como principal contexto para el aprendizaje político, otorgando espacios para la discusión, contraposición y formulación de representaciones sociales sobre lo político. En este escenario surge el principal actor de este proceso que es el del «secundario», que al habitar un nuevo 
espacio de cotidianeidad, «la toma», comienza conversar con otros secundarios sobre temáticas que anteriormente no se conversaban.

Por eso mismo se llegó el tema de las asambleas, en el Liceo como decía Mauricio caímos en un asambleísmo cuático, fue del año 2005 en adelante... comienzan a darse nuevas discusiones y ahí uno va, fue agarrando nuevas herramientas y ahí se cae en un asambleísmo (G4, Mauricio).

Esto pone en el centro del relato generacional, el planteamiento sobre las culturas pre figurativas (Mead, 2006), que indica la existencia de un aprendizaje desde los pares para configurar sus representaciones, en este caso, sobre lo político; los jóvenes se hacen cargo de esa falla «epistemológica» de la aprehensión de la realidad. «Los pares están reemplazando cada vez más a los padres como modelos significativos de conducta, y aquellos que alegan que en verdad estamos ingresando en una etapa totalmente nueva de la evolución cultural» (Mead, 2006:97)

Para el «invierno chileno» tales fuentes no se ven modificadas pero se agregan unas nuevas, las redes sociales. Herramientas como Twitter o Facebook sirven de articuladores de marchas masivas que durante gran parte del año inundan las calles de nuestro país.

Mucho tuvo que ver también con el tema de las redes sociales... o sea todos se congregaban a través de las redes sociales... diciendo que eso... el tratar... el poder manifestarte como ciudadano (G5, Camila).

La dependencia de la relación entre pares pasa a exigir el uso de nuevas tecnologías para articular relatos sobre lo político; de forma de configurar de forma más detalla y eficaz una forma de aprehender la realidad política. Por otro lado aumenta exponencialmente la capacidad de enunciación de los jóvenes, y es que «no piden permiso: se trata de un espacio en que los jóvenes a partir de un yo que asume sin timidez los riesgos de su enunciación, acceden a una posición de autoridad y empoderamiento» (Reguillo, 2012:149). Es así como podemos caracterizar que «los movimientos sociales contemporáneos son descentralizados, fluidos, conectados en red, tecnológicamente sofisticados y simultáneamente locales y globales» (Cardoso, 2006:570).

El carácter relevante de las redes sociales incluso pasa a ser reconocido por generaciones anteriores, el invierno del 2011 se ve reforzado por nuevas tecnologías. 
En ese tiempo internet no estaba tan masivo como es ahora, fotolog y claro Messenger y esas cosas, en realidad se enlazaba con otro pensamiento, y el pensamiento ahora empezaron a discutirse otros conceptos, el tema de la represión del estado a los movimientos sociales, el tema de cómo se manejaba la información (G3, Camila).

c) De protestas, asambleas y marchas: signos dinámicos en los repertorios de acción política en el espacio público

La participación es reconocible como concepto central en cada una de las estructuras de las representaciones sociales de lo político. Pero al adentrarnos en las estructuras reticulares, podemos reconocer que surgen diferencias en los tipos de acción política. Y es que reconocer el proceso de subjetivación de lo político va instalando sentidos del accionar que exigen una constante reconstrucción de su identidad colectiva (Revilla, 1996); permitiéndonos comprender este proceso de constante «actualización» a los tiempos históricos que se ven enfrentados.

La participación de la «voz de los ochenta» tiende a ser clandestina en sus inicios. A medida que la década transcurre las secundarias comienzan a reconocer momentos de apertura que tienen su momento álgido en el Plebiscito de 1988.

Yo creo que también aquí, aparece como lo de lo clandestino en el fondo, porque también los movimientos sociales parten muy muy muy en silencio, muy resguardados, muy pa'callao... empieza masificar un poco más es con las campañas del sí y el no, claro, ahí ya se hace..., es más, permitido (G1, Patricia).

Si observamos las estructuras formuladas para comprender a estas generaciones, podemos reconocer a la aparición del concepto de «protesta», en donde se relata la forma en que se entendía esta (cortes de calle, cacerolazos y jornadas de protesta); se constituían como acciones breves y disruptivas del orden existente hasta el momento.

Claro, lo que te decía yo, hay toque de queda, se cortaba la luz, salíamos a tocar las ollas escondidos, pero éramos todos (G1, Patricia).

Para el movimiento secundario del 2006, la participación adquiere una lógica distinta, comenzando a articularse en base a asambleas, tomas y marchas. 
Yo consideraba en ese tiempo porque la democracia era la evolución máxima de la organización humana..., yo no puedo creer que en Cuarto Medio hablábamos sobre Gramsci y otros locos así que planteaban las organizaciones más horizontales, y votación porque ese es el año en que se hacen muchas asambleas y aparece el tema de la asamblea... nadie no podía decir nada y volver a sus bases a preguntar y la asamblea hacía una votación para saber si aprobaba o rechazaba (G4, Esteban).

Sin el temor a la represión dictatorial de la generación anterior, estos estudiantes tienen la posibilidad «del tiempo» (elemento que la generación de los ochenta carecía dado el cuidado a su identidad) para articular acciones en las cuales no temer ser descubiertos, al contrario, desean ser visibilizados. Una forma distintiva de la participación es la asamblea, que se muestra como momento cardinal de la forma en que se expresa la participación, en donde lo polémico se convierte en una necesidad.

Me recuerdo de que muchos compañeros participaron en lo que era asamblea, salían y tenían que tomar decisiones que tenían que hacer, para apoyar estas causas, que para nosotros, a nivel de liceo, eran desconocidas y que sabíamos que teníamos que apoyarlas. Y dentro de esta, necesariamente, tenían que haber por lo menos dos opiniones o dos opciones (G4, Jonatan).

El 2011 releva el carácter masivo de las marchas. A partir de lo planteado anteriormente sobre las redes sociales, los estudiantes representan la movilización en su carácter masivo. Por otro lado son capaces de articular en esa masividad una propuesta cultural. Resignifican espacios cotidianos de lo urbano los desestructuran de su forma original.

Esta cuestión de que si eran... las diez de la mañana yo puedo salir a marchar si quiero... cruzábamos el puente Llacolén... a pata por un movimiento social... y teníamos el derecho de cruzar ese puente a pata... era... la democracia era el movimiento social... (G5, Fabiola).

El trayecto performativo de la protesta secundaria muestra un carácter fundamentalmente dinámico en este punto. Es así como se pasa de la puesta en escena «silenciosa y clandestina» a una necesariamente «rupturista» que en su acción demostrara que el espacio público es de cada uno de los chilenos. De la contención ochentera a una expresividad obligada por el trayecto y devenir de la protesta social y el contex- 
to político nacional. El impacto que se busca generar, alimenta el sueño, y le otorga el carácter de posible.

Yo me acuerdo que veía en la tele... no sé $p u . .$. y escuchabas no sé $p u . .$. cuarenta mil personas en Concepción y decía... Es caleta de gente... era como sentir mariposas en la guata y pensar que de verdad ibas a cambiar algo (G5, Francisca).

d) La democracia «nuestra»:

La democracia como agente de transformación social

El concepto de democracia tiende a alcanzar un nivel central sobre todo en la primera generación. Este posee una trayectoria propia, que muestra un importante punto de quiebre a partir del «pingüinazo».

Los secundarios de los 80, al definir la democracia como el objeto en base al cual se articula sus relatos, establecen claramente a necesidad de recuperar la representación borrada por el gobierno militar.

También acordándome un poco de lo que comentaba ella, esta cosa como de la historia previa, de la seguridad, del crecimiento económico... era como poner muchas cosas en juego, como arriesgarse (G1, Jessica).

Su desconocimiento práctico motiva en un primer momento una serie de dudas sobre su real conveniencia, pero a partir de la articulación de movimientos de oposición este sentimiento se transforma en una seguridad sobre su necesaria implementación en el país.

Se protestaba, yo escuchaba a la gente protestar, solicitando, democracia, libertades y abogando por los desaparecidos. Ahí yo comencé a hilar. Pero no, pero todos protestaban solicitándola, pero yo no entendía que era democracia porque estábamos bajo un régimen (G2, Guillermo).

A lo anterior se agrega un desconocimiento sobre los partidos políticos, que dado su edad en ese periodo, desconocían totalmente en la práctica. Es así como se articula la idea de «bandos políticos» a favor y en contra de la dictadura.

No había un partido político, no había, era dictadura o era oposición. Ni si quiera se notaba. No había una imagen, como decía ella, en los comerciales del sí y el no aparecieron (G1, Nancy). 
En contraste con el momento anterior la democracia, pese a no ser un elemento central del relato proyectado por los secundarios del 2006, se articula en base a la organización misma del movimiento estudiantil articulado bajo un criterio técnico-funcional.

En esa democracia, en ese espacio para demostrar mi opinión no había un poder... para mí eso es la democracia, un momento de igualdad donde yo podía expresar mi opiniones y que sean tomadas en cuenta (G4, Richard).

Surge una crítica profunda a la forma en que los partidos políticos habían organizado el sistema político chileno y al mismo tiempo una crítica al rol que sus juventudes jugaban en el movimiento estudiantil, lo que es evidenciado en un análisis previo.

Ahora el concepto de democracia yo lo asociaba mucho al sufragio que es el ser ciudadano y a los partidos políticos... no estaba en ningún partido político, no tenía una herramienta de transformación (G3, Camila).

Dado lo anterior, los estudiantes levantan formas de organización y resolución con una fuerte base en la idea de la democracia directa. El cuestionamiento incluso alcanza los liderazgos, que pasan a ser llamados «voceros» y que se busca que tengan un mandato temporal, de forma de propiciar una plataforma para que se escuchara la voz de «la base».

En el Enrique Molina muchas veces lo que se opinaba se podía tergiversar porque un grupo estaba controlando lo que se decía (...) en asamblea pretendían que un vocero fuera rotando (G4, Esteban).

Lo anterior lleva la democracia a un espacio local, situado fundamentalmente en la toma y que reconoce la importancia de la práctica democrática en lo cotidiano, alejándose de la idea de la democracia representativa que se desdibuja en el relato de este periodo (Sandoval y Hatibovic, 2010). Los secundarios del 2011, negocian ciertos planteamientos de los «pingüinos» y vuelven a levantar desde su relato la categoría de líder (con ciertos matices según sexo).

Fue súper desorganizada en comparación a la del 2011 en donde ya habían dirigentes, vocales, voceros y todo eso y claro po, te generaba puntos de foco en donde la gente podía mirar y decir ya esto es lo que quiere (G6, Daniel). 
Profundizando la idea de la heterogeneidad ya planteada por el movimiento anterior. Lo político debe ser un espacio que respete la diferencia, y la nueva democracia parece ser el contexto capaz de permitirlo (Mouffe, 1999).

Y por último la mayoría, era por el tema de que frente a todas las opciones que se nos pudiesen dar, todos los participantes podíamos escuchar, respetábamos que hubiesen opiniones diferente, respetábamos el tema de la diversidad ese año (G4, Jonatán).

En este momento, encontramos principalmente dos tensiones al comparar los relatos generacionales. La reaparición del concepto de líder del 2011 claramente cae en tensión con la idea de la organización de base y directa representada por los jóvenes del 2006. Por otro lado, el quiebre se hace claro frente a la democracia representativa, ya que los primeros se hacen cargo de luchar por ella y los movimientos estudiantiles del nuevo siglo la ven como uno de sus principales oponentes. Así el relato de la democracia radical va adquiriendo fuerza en los movimientos estudiantiles del nuevo siglo; las luchas contra el universalismo liberal articulador de injusticias particulares pondría en movimiento aquellos relatos que desde el estado, nunca desearon explotar su carácter polémico(Mouffe, 1999).

\section{CONSIDERACIONES FINALES}

Frente a lo planteado en momentos anteriores de esta investigación, se vuelve fundamental un momento de síntesis que de forma clara establezca aquellas conclusiones e implicancias de la presente investigación que son importantes de dilucidar sobre todo a la luz de los objetivos y preguntas planteadas. Los cuales proponemos condensar de la siguiente forma.

\section{a) Persistencias estructurales}

El desarrollo de la investigación nos permite dilucidar que estructural y contextualmente existen ciertos elementos que son capaz de persistir en los distintos relatos generacionales. Es así como la crítica a los partidos políticos tradicionales (principalmente de izquierda), el rol de la «información» en la práctica política, el rol central de la justicia 
como objetivo de la práctica política, entre otros, se muestran como espacios continuos del relato generacional postdictadura.

A partir de lo anterior surge un desafío interesante consistente en buscar relatos generacionales secundarios anteriores al evento «bisagra» del Golpe de Estado y ser capaces de identificar si estos elementos son estructurales al relato generacional secundario; es decir, al ser joven.

Por otro lado esta persistencia en las representaciones sociales de lo político de los distintos relatos generacionales nos permitiría plantear elementos nucleares conducentes a hallazgos que caractericen una «representación social juvenil sobre lo político» estructuralmente acorde a los momentos del modelo neoliberal aplicado en nuestro país.

\section{b) Los reventones juveniles como espacios de rearticulación de lo político.}

La lógica en que se presentan los relatos generacionales nos permiten al mismo tiempo que identificar ciertas continuidades estructurales, ser capaz de asignarle a eventos o hitos políticos relevantes un carácter de «transformador» o «actualizador» de la práctica política. El relato generacional se muestra también como una construcción determinada a cierto tiempo/contexto socio histórico.

En torno a estos «reventones» juveniles vuelven a aparecer ciertas categorías abandonadas (como el ciudadano), se adaptan a cambios políticos y por lo tanto se asignan nuevas territorialidades (de la iglesia a la toma) y su organización se ve modificada a partir de un análisis pragmático del tiempo histórico que viven (de lo clandestino a la «puesta en escena» de las marchas estudiantiles) y conceptos centrales son negociados en su significado (de la lucha por ser representados, a la lucha por representarse). Esto nos permitiría conocer que los tiempos históricos se mueven de forma compleja, en donde no solamente encontramos grandes hitos a nivel fundacional, sino que unos distintos a nivel «periférico» pero con una gran incidencia en la práctica política.

Dentro de esta lógica observamos que el 2006 se muestra como un momento de ruptura en el sentido de las representaciones sociales de lo político, sobre todo en su carácter «asambleístico». En ese sentido podemos entender la generación juvenil del siglo XXI en dos fases distintas: como ruptura/aprendizaje durante el 2006, mostrándose como un momento de enlace generacional en dónde son capaces de «construir» nuevas herramientas de performatividad política desde 
una memoria familiar/histórica (sobre todo puesto en juego en grupos focales de mujeres). Por otro lado, el 2011 se transforma en una apuesta por la captura de lo político a nivel nacional, asumiendo gran parte de los productos del 2006 y reformulándolo a partir de los nuevos objetivos planteados.

\section{c) La propuesta polémica del relato generacional del siglo XXI}

La investigación nos muestra que el relato de la transición principalmente en su carácter consensuado se observa desgastado, ya que se le imprime una capacidad para conservar el poder en ciertos espacios y grupos. Al mismo tiempo se le reconoce como una forma de hacer política incapaz de representar a todos, y que elimina la diferencia y la heterogeneidad.

Las representaciones sociales de lo político construidas por estudiantes secundarios durante el siglo XXI imprime fundamentalmente su alto respeto por el individuo y sus diferencias, lo que levanta las propuestas que desde hace 20 años venía planteado la escuela de la democracia «agónica». Los estudios de Rancière, Mouffe y Bourdieu se hacen indispensables para leer la forma en que los jóvenes están construyendo relatos en torno a la política y nos permitiría de cierta forma proponer un modelo de trabajo que los incluya como actores fundamentales del proceso de «organización de la polis» y no los lleve a los márgenes de la práctica política (desde donde han mostrado ser enriquecedores de la práctica política).

d) El «pinguinazo» y el «invierno chileno».
¿Distintos momentos de un mismo relato generacional?

El trabajo de investigación plantea una tensión con las decisiones metodológicas empleadas en el desarrollo de esta. Como se observa en páginas anteriores podemos indicar que se había «asumido» la existencia de dos relatos generacionales a partir de la idea de definir «hitos» políticos similares, como lo son el «pingüinazo» del 2006 y el «invierno chileno» del 2011. Luego del análisis desarrollado podemos indicar que no existe la suficiente información para relevar la idea de que sean dos relatos generacionales distintos; es decir, dos generaciones distintas. Por lo que podríamos desechar parte de nuestra hipótesis de trabajo que reconocía en ambos eventos la aparición de generaciones distintas. Existen una serie de momentos en donde surgen conti- 
nuidades entre ambos relatos lo que nos indicaría que pueden ser distintos momentos de un mismo relato, el de los primeros jóvenes del siglo XXI.

Al mismo tiempo plantea una discusión interesante. En la construcción de la investigación, se asumieron dos hitos relevantes en donde las juventudes pusieron en el centro de su práctica lo político, pero pese a su carácter similar, uno se muestra como un hito fundante en contraste con otro que muestra una profundización y aprendizaje del primer momento. Es así como podemos definir que pese al carácter de hito que ambos poseen, no necesariamente se comportan como momentos «bisagras» de las representaciones sociales de los relatos generacionales. Lo anterior confirma la necesidad planteada por autores como Abrams, Bourdieu y Muñoz de la necesidad de caracterizar densamente los eventos que se establecen como «definitorios» de una generación, y entender las lógicas complejas de los tiempos históricos.

CONCEPCIÓN (CHILE), MAYO 2015

RECIBIDO: JUNIO 2015 ACEPTADO: JUNIO 2015

\section{REFERENCIAS BIBLIOGRÁFICAS}

ABRAMS, P. (1982): Historical Sociology. Shepton Mallet: Open Books.

ABRIC, J. (1993): Central System, Peripheral System: Their Functions and Roles in the Dynamic of Social Representations. Papers on Social Representations, Vol. 2, No2.

_ (2001): Prácticas sociales y representaciones. México D.F: Coyoacán.

Aguilera, O. (2009): «Los estudios sobre la juventud en Chile: Coordenadas para un estado del arte». Última Década, Vol. 17, N³1. Valparaíso: Ediciones CIDPA.

ALTHUSSER, L.S. (1988): Ideología y aparatos ideológicos de Estado: Freud y Lacan. Buenos Aires: Nueva Visión.

Aristóteles (2006): Política. Madrid: S.L.U Espasa Libros.

Barrionuevo, A. (2011): «With Kiss-ins and Dances, Young Chileans Push for Reform». New York Times.

BARTHES, R. (1977): «Introducción al análisis estructural de los relatos». En SilviA NiCCOLINI (comp.) El análisis estructural. (págs. 9-45). Buenos Aires: Centro Editor de América Latina.

Bellei, C. y C. CABAlin (2013): «Chilean Student Movements: Sustained Struggle to Transform a Market-oriented Educational System». Current Issues in Comparative Education, Vol.15, №2. 
BERGER, P. y T. LUCKMANN (1995): La construcción social de la realidad. Buenos Aires: Amorrortu.

BERNSTEIN, B. (1993): La construcción social del discurso pedagógico: textos seleccionados. Madrid: Producciones y Divulgaciones Culturales y Científicas, El Griot.

BONIFACE, P. (2005): «Política, medios y opinión pública». Vanguardia Dossier.

(2012): Las estrategias de la reproducción social. Madrid: Siglo XXI Editores.

- (2003): Cuestiones de Sociología. Madrid: Ediciones Istmo.

(2011): Cuestiones de Sociología. Madrid: Akal.

(2012): Bosquejo de una teoría de la práctica. Buenos Aires: Prometeo Libros.

(1992): El sentido práctico. Madrid: Taurus Ediciones.

(2003): Los herederos: los estudiantes y la cultura. . Buenos Aires: Siglo Veintiuno Editores.

— (1997): Razones prácticas. Sobre la teoría de la acción. Barcelona: Anagrama.

BourdiEU, P. (1992): El sentido práctico. Madrid: Taurus Ediciones.

CANDÍA, E. (2004): «El movimiento político sin voto de los jóvenes en Chile». Observatorio de Juventud.

CARDENAS, C. (2014): «Representación de la acción política de los estudiantes chilenos: movilización de significados en redes sociales. Última Decada.

CARdoso, G. (2006): Os media na sociedade em rede. Lisboa: Fundaçao Calouste Gulbenkian.

CEJU (2010): «Nuevas prácticas políticas en jóvenes de Chile: conocimientos acumulados 2000-2008». En V. AlVARAdO y P. VOMMARO: Jóvenes, cultura y política en América Latina: algunos trayectos de sus relaciones, experiencias y lecturas (1960-2000). Rosario: Homo Sapiens Ediciones.

FoucAult, M. (2002): El orden del discurso. Barcelona: Tusquets. (1992): El orden del discurso. Mexico D.F: Tusquets editores. (2012): Vigilar y castigar. Madrid: Biblioteca Nueva.

FRANZÉ, J. (2010): «Migración y política: latinoamericanos en la Comunidad de Madrid». En R. DE LA FUENTE: La política como proceso de subjetivación: un estudio de caso sobre los inmigrantes latinoamericanos en Madrid. Madrid: Trama.

FUNES, M. (2003): «Socialización política y participación ciudadana. Jóvenes en dictadura y jóvenes en democracia». Revista de Estudios de Juventud.

GARRETón, M. (2003): Incomplete democracy: political democratization in Chile and Latin America. Chapell Hill: UNC Press Books.

Huffington POST (25 de Agosto de 2011): «Chile 'Thriller' Protest: Students Stage Michael Jackson Dance For Education Rally». Estados Unidos. 
KornBlit, A. L. (2004): Metodologías cualitativas en ciencias sociales: Modelos y procedimientos de análisis. Buenos Aires.: Editorial Biblos.

LA NACIÓN (4 de noviembre de 2011): «1800 horas por la educación sigue recorrido por 60 ciudades de Chile». Chile.

LAU, R. y O. SEARS (1986): Political cognition: The 19th Carnegie MellonSymposium on Cognition. Hillsdale, N. J.: awrence Erlbaum Associates.

LEYTON, D. (2009): «Jóvenes. Una aproximación para abordar los problemas de la inclusión y reproducción social juvenil». Revista Sociológica de Pensamiento Crítico.

MANNHEIM, K. (2003): «El problema de las generaciones». Revista Española de Investigaciones Sociológicas.

MARTineZ, M. (2003): «Epistemología Feminista y Postmodernidad». Cinta de Moebio, Revista de Epistemología de Ciencias Sociales.

MAYOL, A. (2012): No al lucro.De la crisis del modelo a la nueva era política. Santiago: Debate.

MEAD, M. (2006): Cultura y compromiso. Barcelona: Gedisa.

MonTECINOS, S. (1988): «Identidad femenina y modelo mariano en Chile». En E. Hola: Mundo de mujer:continuidad y cambio. Santiago: CEDEM.

Moulian, T. (1997): Chile actual: Anatomía de un mito. Santiago de Chile: LOM Ediciones.

MOUFFE, C. (1999): El retorno de lo político: comunidad, ciudadanía, pluralismo, democracia radical. Barcelona: Paidos Ibérica.

MuÑOZ, V. (2011): Generaciones: juventud universitaria e izquierdas políticas en Chile y México (Universidad de CHILE UNAM 1984-2006). Santiago: LOM Ediciones.

(2004): «Imágenes y estudios cuantitativos en la construcción social de juventud en Chile. Un acercamiento histórico». Última Década.

ORTEGA y J. GASSET (1970): El tema de nuestro tiempo. Madrid: Revista de Occidente.

Ranciere, J. (1996): El desacuerdo. Política y filosofía. Buenos Aires: Nueva Visión Argentina.

- (2002): El maestro ignorante: cinco lecciones sobre la emancipación intelectual. Barcelona: Laerte, S. A. de Ediciones. (2010): Momentos políticos. Buenos Aires: Capital Intelectual. (2006): Política, policía, democracia. Santiago: LOM Ediciones.

- (2004): Who is the Subject of the Rights of Man? The South Atlantic Quarterly.

REGUILlO, R. (2012): Culturas juveniles: formas políticas del desencanto. Buenos Aires: Siglo Veitiuno Editores.

REVILLA, M. (1996): «El concepto de movimiento social: acción, identidad y sentido». Última Década. 
RODRÍGUEZ, T. G. (2007): Representaciones sociales. Teoría e investigación. Guadalajara: Centro Universitario de Ciencias Sociales y Humanidades, Editorial CUCSH-UDG.

SCOTT, J. (1996): «El género: una categoría util para el análisis histórico». En M. Lamas: El género: La construcción cultural de la diferencia sexual. Mexico D.F: Miguel Angel Porrúa.

(2003): «Historia de las mujeres». En P. Burke: Formas de hacer historia. Madrid: Alianza.

SAlAZAR, G. (2012): Movimientos sociales en Chile. Trayectoria histórica y proyección política. Santiago: Uqbar.

— y J. Pinto (2010): Historia contemporánea de Chile IV: hombría y feminidad. Santiago: LOM Ediciones.

— $\mathrm{y}-$ (2010): Historia contemporánea de Chile V: niñez y juventud. Santiago de Chile: LOM Ediciones.

SANDOVAL, J. (2003): «Ciudadanía y juventud: el dilema entre la integración social y la diversidad cultural». Última Década.

— y F. HATIBOVIC: (2010): «Socialización política y juventud: el caso de las trayectorias ciudadanas de los estudiantes universitarios de la Región de Valparaíso». Última Década.

Segovia, C., y R. GAmbOA (2012): «Chile: el año en que salimos a la calle». Revista de Ciencia Política.

Venegas, H. (2009): «Trayectoria del Partido Comunsita de Chile: de la crisis de la Unidad Popular a la política de rebelión popular de masas». Universum.

WILLIS, P. (1988): Aprendiendo a trabajar. Madrid: Ediciones Akal.

ZARZURI, R. (2006): «Participación juvenil, cultura y movimientos». Observatorio de Juventud. 